Check for updates

Cite this: RSC Adv., 2018, 8, 30860

Received 12th July 2018

Accepted 17th August 2018

DOI: $10.1039 / \mathrm{c} 8 \mathrm{ra05947k}$

rsc.li/rsc-advances

\section{Potassium iodide-polyethylene glycol catalyzed cycloaddition reaction of epoxidized soybean oil fatty acid methyl esters with $\mathrm{CO}_{2}^{\dagger} \uparrow$}

\begin{abstract}
Wei Liu, (D)*abc Guanghui Lu, ${ }^{a}$ Bing Xiao ${ }^{a}$ and Chenfei Xie ${ }^{b}$
Nowadays, the clean production of bio-based products and fixation of carbon dioxide $\left(\mathrm{CO}_{2}\right)$ are highly desirable. In this work, carbonated fatty acid methyl esters have been successfully prepared in $99 \%$ yield by cycloaddition of $\mathrm{CO}_{2}$ with bio-based epoxidized methyl soyates. This was accomplished with a simple and cheap catalyst system of polyethylene glycol 400 (PEG-400) and potassium iodide (KI) under solvent-free conditions. Experimental parameters such as the molar ratio of polyethylene glycol to metal halide, catalyst loading, reaction temperature, reaction time and $\mathrm{CO}_{2}$ pressure were systematically evaluated. The PEG-400 and KI co-catalysts (4 mol\%) could significantly promote the cycloaddition of $\mathrm{CO}_{2}$ with internal epoxides (epoxidized methyl soyates) to produce carbonated fatty acid methyl esters. FT-IR and NMR analyses were used to confirm the product, and $99 \%$ yield of the five-membered cyclic carbonated methyl soyates was obtained at $120{ }^{\circ} \mathrm{C}$ with $3.0 \mathrm{MPa}$ pressure of $\mathrm{CO}_{2}$ for $20 \mathrm{~h}$. This method provides a cleaner approach for the production of bio-based products.
\end{abstract}

\section{Introduction}

Carbon dioxide $\left(\mathrm{CO}_{2}\right)$ is a major component of greenhouse gases and is produced by the combustion of fossil fuels, the fermentation of sugar and the respiration of all living organisms. ${ }^{1}$ Moreover, $\mathrm{CO}_{2}$ is considered as an abundant, low-cost, non-toxic and renewable $\mathrm{C} 1$ resource. Therefore, the applications of $\mathrm{CO}_{2}$ have rapidly become a subject of interest in the academic and industrial sectors. ${ }^{2}$ In the past two decades, the utilization of $\mathrm{CO}_{2}$ transformation has mainly focused on the following areas: (a) reacting with hydrogen to produce methanol, hydrocarbons and their derivatives, ${ }^{3-5}$ (b) reacting with ammonia to form urea, ${ }^{6}$ (c) cycloaddition with epoxides to form carbonates or polycarbonates. ${ }^{7,8}$

In recent years, the cycloaddition reaction of $\mathrm{CO}_{2}$ has become one of the hot fields in catalysis (e.g. heterogeneous catalysts $)^{9-11}$ for its production of value-added organic chemicals (e.g. cyclic carbonates) from the renewable $\mathrm{C} 1$ building block. Cyclic carbonates are one of the special fine chemical products. Because of their advantages of high boiling points, excellent biodegradability and solubility, cyclic carbonates can

${ }^{a}$ College of Food Science and Technology, Henan University of Technology, Lianhua Street 100, Zhengzhou 450001, Henan Province, P. R. China

${ }^{b}$ College of Chemistry and Molecular Engineering, Zhengzhou University, Science Avenue 100, Zhengzhou 450001, Henan Province, P. R. China

'Xuchang Quality Supervision and Testing Center, Longxin Street, Xuchang 461000, Henan Province, P. R. China. E-mail: liuwei307@hotmail.com; Fax: +86-37167758022; Tel: $+86-371-67758022$

$\dagger$ Electronic supplementary information (ESI) available. See DOI: $10.1039 / \mathrm{c} 8 \mathrm{ra} 05947 \mathrm{k}$ be widely used as one of the main raw material for polycarbonates $^{\mathbf{1 2}}$ and in other plastic industries such as nonisocyanate polyurethanes. ${ }^{13}$ Five-membered cyclic carbonates, as a member of the cyclic carbonates, are often used as electrolyte solvents in lithium-ion batteries, ${ }^{\mathbf{1 4}}$ plasticizers, ${ }^{\mathbf{1 5}}$ environment friendly aprotic polar organic solvents, ${ }^{\mathbf{1 6}}$ fuel additives, ${ }^{17}$ starting materials and intermediates in the manufacture of fine chemicals. ${ }^{18}$

The cycloaddition reaction of $\mathrm{CO}_{2}$ to epoxides depends on the type of catalyst used. Therefore, the biggest challenge is the development of efficient catalysts to promote the cycloaddition reaction under moderate reaction conditions. Over the past decades, a lot of researchers have focused on the development of efficient homogeneous catalysts ${ }^{\mathbf{1 9}}$ and heterogeneous catalysts (e.g. metal-organic frameworks $)^{10}$ for these reactions. Due to their high catalytic activity, homogeneous catalysts, such as quaternary ammonium salts (e.g. TBAB), ${ }^{20,21}$ metal complexes, ${ }^{22}$ ionic liquids, ${ }^{23}$ organocatalysts ${ }^{24}$ and crown ether complexes ${ }^{25}$ have received significant attention. However, it is still very desirable to explore simple and efficient catalyst systems for this important transformation.

Polyethylene glycols (PEGs) are well known as inexpensive, thermally stable, toxicologically innocuous, environmentally benign media to chemical, pharmaceutical and food industries, ${ }^{26}$ and are commercially available on large scales for economical prices. In particular, they are also used as phase transfer catalysts (PTC) in some cases and reports indicate that $\mathrm{CO}_{2}$ can weakly interact with ether linkage of PEGs, which leads to the improvement of $\mathrm{CO}_{2}$ adsorption rates. ${ }^{27}$ Furthermore, the hydroxyl moieties of PEGs should benefit the cyclic-carbonate 
formation by substrate activation through hydrogen bonding. ${ }^{28}$ Metal halides (e.g. $\mathrm{ZnBr}_{2}$ ) are also effective catalysts for catalytic cycloaddition reaction of epoxides and $\mathrm{CO}_{2}$. However, there is virtually no catalytic activity when only these metal halides are used. Therefore, coordination of additives or phase transfer catalysts is usually required..$^{29-34}$

In line with the development of green and sustainable chemistry, it is of great importance to prepare value-added products from bio-based epoxides. ${ }^{35,36}$ Carbonated methyl soyates (CMS), which were prepared through the cycloaddition of $\mathrm{CO}_{2}$ with epoxidized soybean oil fatty acid methyl esters, represent a useful and sustainable chemical intermediate. Soybean oil fatty acid methyl esters (methyl soyate) are one of the typical vegetable oil fatty acid methyl esters prepared from soybean oil. Due to the steric hindrance of the epoxide groups in methyl soyate, efficient catalysts for the preparation of carbonated methyl soyates are limited. ${ }^{24,30,37}$ In the present work, we explored the catalytic performance of cheap and green PEGs and $\mathrm{KI}$ for cycloaddition of $\mathrm{CO}_{2}$ with epoxidized methyl soyates (EMS) to produce carbonated methyl soyates (CMS) (Scheme 1). Particularly, the role of PEGs in this cycloaddition reaction was investigated. The CMS product was identified by both FT-IR and NMR analysis.

\section{Results and discussion}

\subsection{Catalyst screening for the carbonation of EMS}

PEG-400-embedded-KBr (i.e. $\left[\mathrm{K}^{+}\{\mathrm{PEG}\} \mathrm{Br}^{-}\right]$) has been reported as an efficient catalyst for the cycloaddition of terminal epoxides (e.g. styrene oxide) with $\mathrm{CO}_{2}$, and $\left[\mathrm{K}^{+}\{\mathrm{PEG}\} \mathrm{Br}^{-}\right]$exhibited higher efficiency than the mixture of PEG- 400 and $\mathrm{KBr}$ in the study. ${ }^{29}$ Considering the simple preparation, low cost and sustainability of this catalyst, we embarked our investigation on the cycloaddition of EMS with $\mathrm{CO}_{2}$ using $\left[\mathrm{K}^{+}\{\mathrm{PEG}\} \mathrm{Br}^{-}\right]$as the catalyst (Scheme 2). We conducted the cycloaddition of EMS with $\mathrm{CO}_{2}(10 \mathrm{~atm})$ at $120^{\circ} \mathrm{C}$. However, the results indicated that no carbonation of EMS occurred in the presence of $\left[\mathrm{K}^{+}\{\mathrm{PEG}\}\right.$ $\left.\mathrm{Br}^{-}\right]$. This may be because $\left[\mathrm{K}^{+}\{\mathrm{PEG}\} \mathrm{Br}^{-}\right]$is not suitable for substrates with larger steric hindrance (e.g. EMS). Herein, we revisited the combination of PEG and metal halides to develop an efficient cycloaddition catalyst system for the bio-based EMS.
The reaction conditions for the initial screening were as follows: $120{ }^{\circ} \mathrm{C}, 1.0 \mathrm{MPa}$ pressure of $\mathrm{CO}_{2}$, reaction time of $18 \mathrm{~h}$ under solvent-free condition (Table 1). It is noteworthy that no cycloaddition product was observed using only KI as the metal halide (Table 1, entry 1). Poly(ethylene glycol)s (PEGs) are of particular interest because their properties can be tuned by their size and their large-scale commercial availability at low costs. ${ }^{30}$ PEG can be used as phase transfer catalysts (PTC) and green solvent in most cases. ${ }^{38}$ In general, when the commonly used potassium iodide (KI) in combination with PTC $(1: 1$, mol $\mathrm{mol}^{-1}$ ) was used as the co-catalyst system for the cycloaddition reaction of EMS, the yields of CMS significantly improved with the increase in molecular weight of the PEGs (Table 1, entries 2$11)$. When ethylene glycol or triethylene glycol $(\mathrm{MW}=150)$ were used as the PTC (Table 1, entries 2 and 3), the yields of CMSs were less than $5 \%$ and $10 \%$, respectively. Cycloaddition using tetraethylene glycol (MW = 194) or PEG-200 as the PTC resulted in CMS yields of $52 \%$ and $55 \%$, respectively (Table 1, entries 4 and 5). Subsequently, the yields of CMSs increased (74-79\%) with larger molecular weight PEGs (PEG-400, PEG-600, PEG-800, PEG-1000, PEG-2000 and PEG-4000) (Table 1, entries 6-11). This is probably because the solubility of these PEGs is not limited with the substrates at the reaction temperature of $120{ }^{\circ} \mathrm{C}$.

For comparison, we also explored the cycloaddition reaction of EMSs and $\mathrm{CO}_{2}$ catalyzed by other metal iodides (e.g. NaI, $\mathrm{CaI}_{2}$ ) (Table 1, entries 12-14). The yield of CMSs catalyzed by sodium iodide (NaI) in cooperation with PEG-400 was $65 \%$. However, NaI was less attractive due to the low catalytic activity compared with that of KI. Calcium iodide $\left(\mathrm{CaI}_{2}\right)$ or zinc iodide $\left(\mathrm{ZnI}_{2}\right)$ showed no activity for this reaction under the same reaction conditions $\left(120{ }^{\circ} \mathrm{C}, 1.0 \mathrm{MPa}\right.$ pressure of $\left.\mathrm{CO}_{2}\right)$ in combination with PEG-400. This might be due to the higher dissociation energy needed by $\mathrm{CaI}_{2}$ and $\mathrm{ZnI}_{2}$ to form $\mathrm{Ca}^{2+}, \mathrm{Zn}^{2+}$ and $\mathrm{I}^{-}{ }^{39}$ in this case. Finally, the combination of potassium bromide $(\mathrm{KBr})$ and PEG-400 for the cycloaddition reaction of EMS and $\mathrm{CO}_{2}$ was investigated (Table 1, entry 15). The results showed that $\mathrm{KBr}$ had no activity for this cycloaddition reaction similar to the $\left[\mathrm{K}^{+}\{\mathrm{PEG}\} \mathrm{Br}^{-}\right]$complex (Scheme 2). Considering PEG-400 as the most commonly used PEG, KI in cooperation with PEG-400 was selected as the optimum catalyst system to explore the cycloaddition reaction of EMS with $\mathrm{CO}_{2}$ in the following experiments.

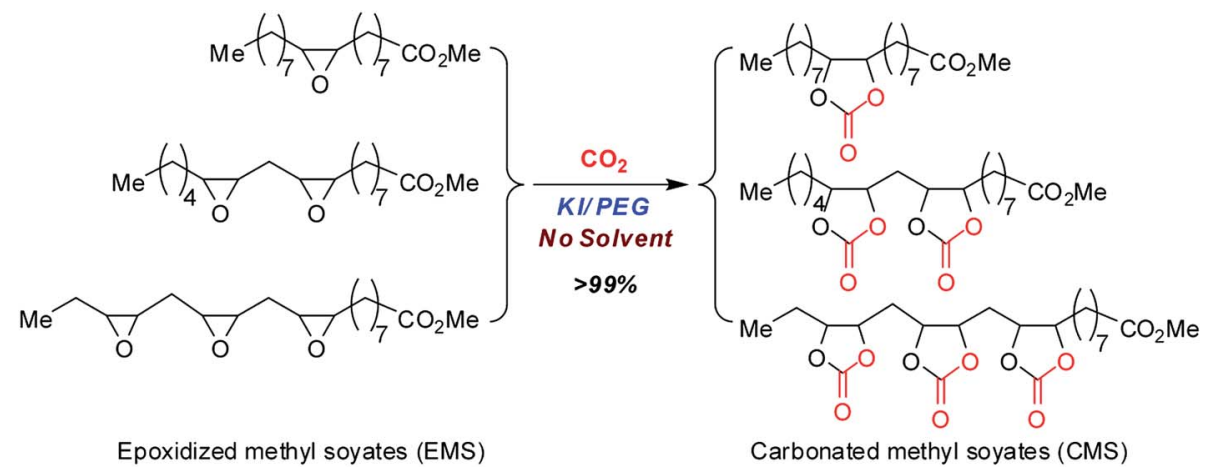

Scheme 1 Cycloaddition of $\mathrm{CO}_{2}$ with EMS. 
Previous work (Ref: 29)

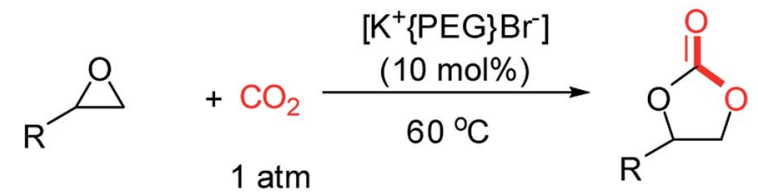

This work

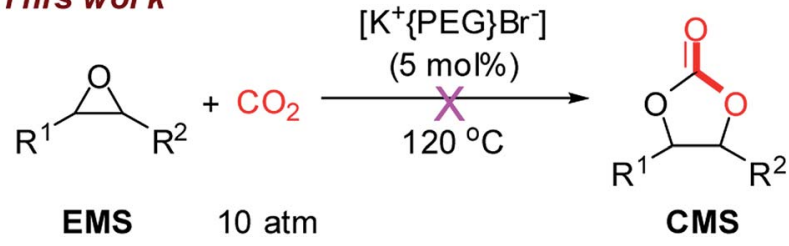

Scheme 2 Cycloaddition catalyzed by $\left[\mathrm{K}^{+}\{\mathrm{PEG}\} \mathrm{Br}^{-}\right]$complex.

\subsection{Effect of the molar ratio of KI to PEG-400}

In the catalyst screening experiments, the amount of metal halide and PTC were both $5 \mathrm{~mol} \%$. We hypothesized that the molar ratio of metal halide (e.g. KI) to PTC had an impact on the cycloaddition reaction of EMS and $\mathrm{CO}_{2}$ to prepare CMS. Therefore, the effect of molar ratio of KI to PEG-400 $(5: 1,5: 3$, $5: 5,5: 8$ and $5: 10)$ on the cycloaddition reaction of EMS with $\mathrm{CO}_{2}$ was investigated (Fig. 1).

Yields of CMS increased as the molar amount of PEG-400 increased from $1 \mathrm{~mol} \%$ to $5 \mathrm{~mol} \%$, producing CMS in $79 \%$ yield. Subsequently, the molar amount of PEG-400 was increased to $8-10 \mathrm{~mol} \%$ in order to investigate the PTC effect,

Table 1 Catalyst screening for the carbonation of EMS ${ }^{a}$

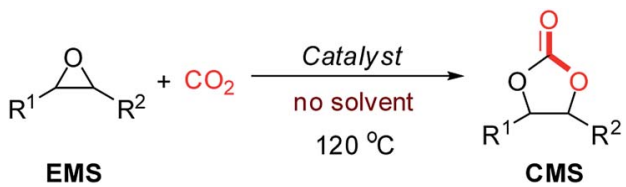

\begin{tabular}{lllc}
\hline Entry & Metal salt & PTC & Yield (\%) \\
\hline 1 & KI & - & 0 \\
2 & KI & Ethylene glycol & $<5$ \\
3 & KI & Triethylene glycol & 10 \\
4 & KI & Tetraethylene glycol & 52 \\
5 & KI & PEG-200 & 55 \\
6 & KI & PEG-400 & 79 \\
7 & KI & PEG-600 & 78 \\
8 & KI & PEG-800 & 78 \\
9 & KI & PEG-1000 & 74 \\
10 & KI & PEG-2000 & 74 \\
11 & KI & PEG-4000 & 78 \\
12 & NaI & PEG-400 & 65 \\
13 & CaI & PEG-400 & 0 \\
14 & ZnI & PEG-400 & 0 \\
15 & KBr & PEG-400 & 0
\end{tabular}

${ }^{a}$ Reaction conditions: reaction temperature: $120^{\circ} \mathrm{C}$; reaction time: $18 \mathrm{~h}$; $\mathrm{CO}_{2}$ pressure: $1.0 \mathrm{MPa}$; stirring speed: $400 \mathrm{rpm}$; catalyst loading: 5 mol\%; PTC concentration: 5 mol\%; EMS: $5.0 \mathrm{~g}$.

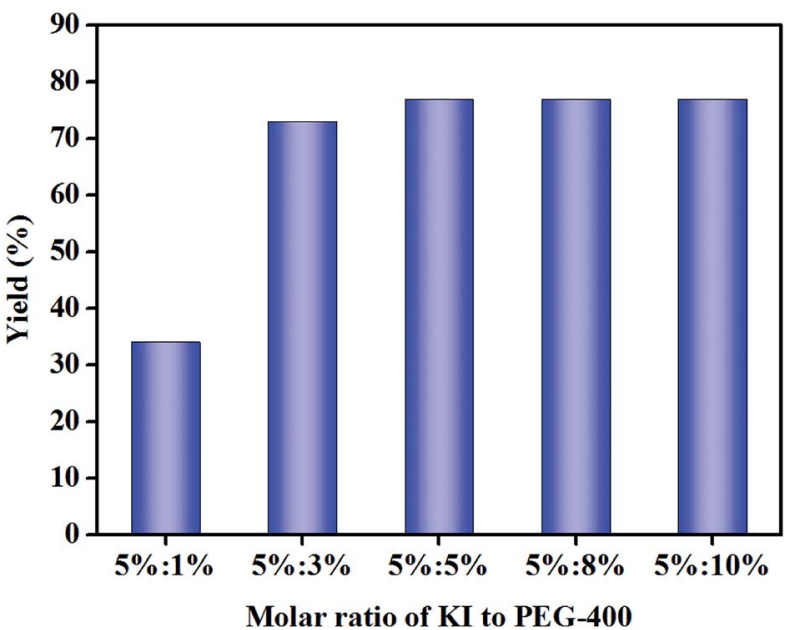

Fig. 1 The effect of molar ratio of KI to PEG-400 on cycloaddition reaction. (Reaction conditions: reaction temperature: $120{ }^{\circ} \mathrm{C} ; \mathrm{CO}_{2}$ pressure: $1.0 \mathrm{MPa}$; reaction time: $18 \mathrm{~h}$; stirring speed: $400 \mathrm{rpm}$; EMS: 5.0 g.)

and it was observed that the yield of CMS remained constant. We proposed that one molecule of KI salt reacts with one unit of PEG-400 in situ to afford the $\left[\mathrm{K}^{+}\{\mathrm{PEG}\} \mathrm{I}^{-}\right]$complex (Scheme 3), ${ }^{29}$ which may act as the true catalyst for such a cycloaddition reaction. On the other hand, PEG-400 can coordinate with the $\mathrm{K}^{+}$from KI, which reduces the interaction between $\mathrm{K}^{+}$and $\mathrm{I}^{-}$to increase the nucleophilicity of $\mathrm{I}^{-}$, thus enhancing the catalytic activity of KI. It can be seen that the highest yield was achieved for the molar ratio of KI to PEG-400 of $1: 1$. Therefore, the combination of KI/PEG-400 (1:1, mol mol $\left.{ }^{-1}\right)$ was selected for the following optimization experiments.

\subsection{Effect of other reaction parameters on the yield of CMS}

The effect of other reaction parameters (e.g. catalyst concentration, reaction temperature, reaction time and $\mathrm{CO}_{2}$ pressure) on the yield of CMS were systematically investigated (Fig. 2). The catalyst concentration is one of the most important factors affecting the yield of CMS. Therefore, a suitable concentration of the catalyst is required. A set of experiments on the catalyst concentration were performed and the results are shown in Fig. 2a. The results indicate that the yields of CMS increased with the increase in catalyst concentration and a high yield of CMS (85\%) was obtained at $8 \mathrm{~mol} \% \mathrm{KI} / \mathrm{PEG}-400$. Increasing the catalyst concentration further (10 mol\%) led to an almost constant yield under the used reaction conditions. Therefore, the optimum catalyst concentration of $8 \mathrm{~mol} \%$ was used in the following experiments.

The reaction temperature is another important parameter that affects the cycloaddition reaction. The oxirane groups are

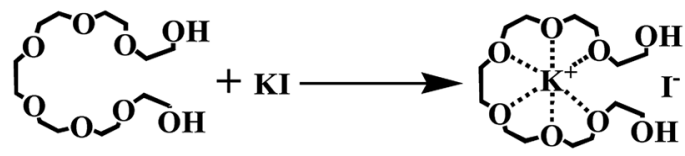

Scheme 3 Proposed formation of $\left[\left.\mathrm{K}^{+}\{\mathrm{PEG}\}\right|^{-}\right]$complex. 

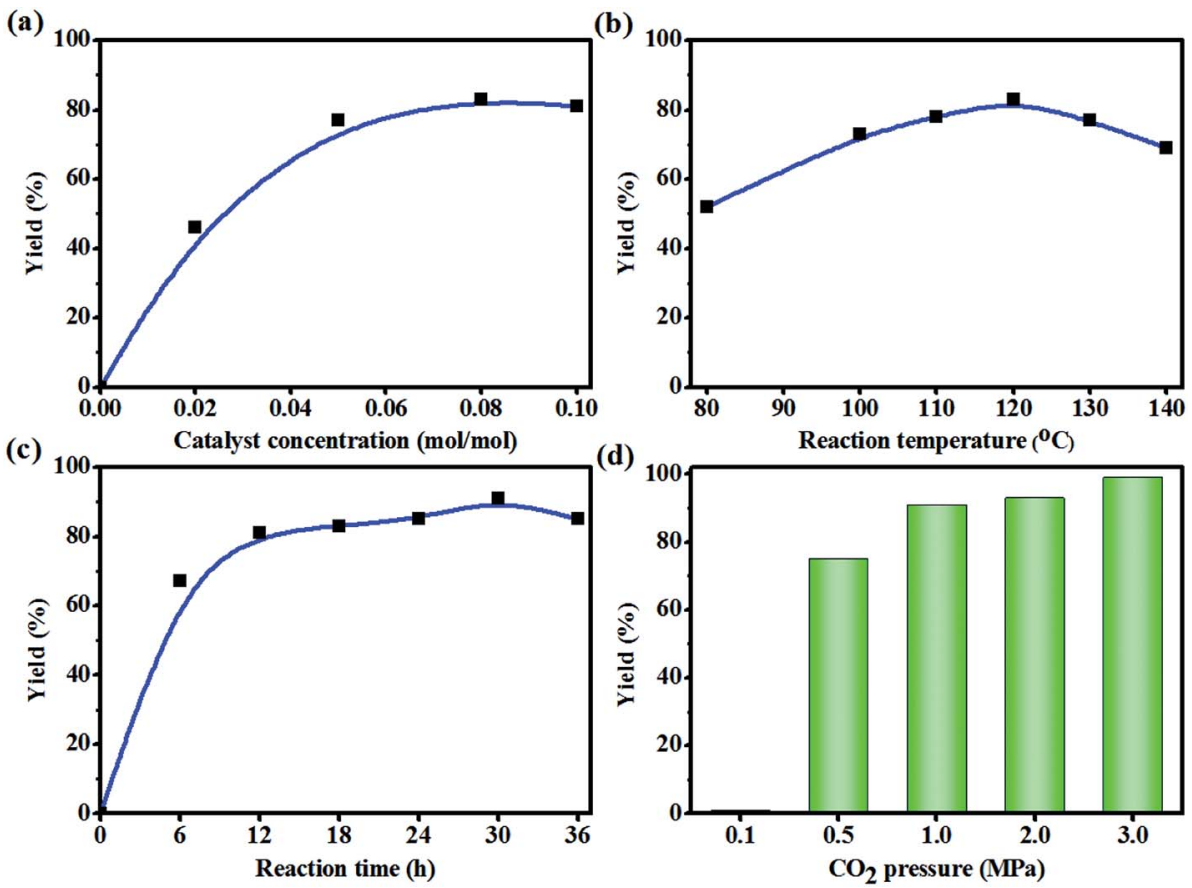

Fig. 2 Effects of (a) catalyst concentration, (b) reaction temperature, (c) reaction time, (d) $\mathrm{CO}_{2}$ pressure on the yield of $\mathrm{CMS}$. (Reaction conditions: (a) $120^{\circ} \mathrm{C}, 1.0 \mathrm{MPa}, 18 \mathrm{~h}$; (b) catalyst concentration $8 \mathrm{~mol} \%, 1.0 \mathrm{MPa}, 18 \mathrm{~h}$; (c) catalyst concentration $8 \mathrm{~mol} \%, 120{ }^{\circ} \mathrm{C}, 1.0 \mathrm{MPa}$; (d) catalyst concentration $8 \mathrm{~mol} \%, 120^{\circ} \mathrm{C}, 30 \mathrm{~h}$.)

located in the middle of the molecular chain of the EMS, which results in a larger steric hindrance. So a relatively higher reaction temperature was employed. Experiments were conducted at different temperatures $\left(80-140^{\circ} \mathrm{C}\right)$ to investigate the effect of temperature on the yield of CMS (Fig. 2b). It is evident that the yield of CMS increased with the increase in temperature (80-120 $\left.{ }^{\circ} \mathrm{C}\right)$. However, higher temperatures $\left(>130{ }^{\circ} \mathrm{C}\right)$ led to possible side-reactions, such as epoxy ring opening reaction. Therefore, an operating temperature of $120{ }^{\circ} \mathrm{C}$ was selected for the subsequent investigations.

Fig. 2c displays the influence of reaction time on the CMS yield. It was noted that the CMS yield increased with prolongation of the reaction time. In detail, the CMS yields increased rapidly with the increase in reaction time until it reached $12 \mathrm{~h}$. With further prolonging the reaction time, the yields of carbonated methyl soyates increased slowly and reached a maximum $(91 \%)$ with a reaction time of $30 \mathrm{~h}$. This phenomenon was probably due to the increased steric hindrance caused by the formation of cyclic carbonate groups from two or three oxirane groups located in the same molecular chain (Scheme 4). Besides, the absorption rate of $\mathrm{CO}_{2}$ increased in the following order: carbonated vegetable oils < epoxidized vegetable oils. ${ }^{40}$ In other words, the concentration of $\mathrm{CO}_{2}$ in the reaction system declined rapidly with increasing yields of CMS. Thus, $30 \mathrm{~h}$ was selected as the optimal reaction time.

In terms of gas-liquid two-phase reactions, the $\mathrm{CO}_{2}$ pressure also plays an important role on the cycloaddition reaction. As shown in Fig. 2d, the CMS yields were significantly affected by $\mathrm{CO}_{2}$ pressure. Notably, nearly no reaction was detected under $0.1 \mathrm{MPa} \mathrm{CO}_{2}$ pressure. The CMS yields increased when the pressure of $\mathrm{CO}_{2}$ increased from 0.1 MPa to 3.0 MPa. In general, the yields of the cycloaddition reaction were increased with

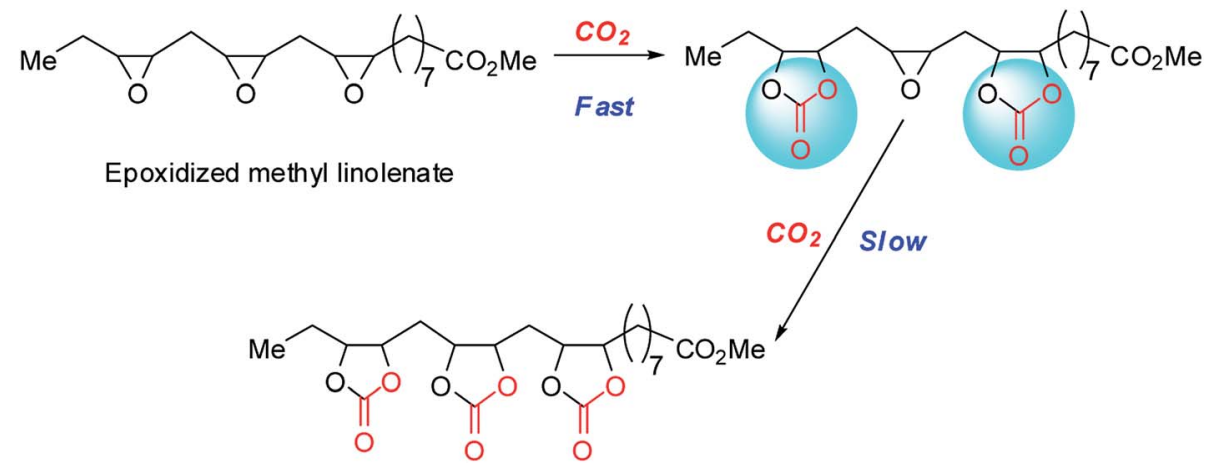

Scheme 4 Stepwise reaction for the carbonation of epoxidized methyl linolenate. 
increase in $\mathrm{CO}_{2}$ pressure. The reason for this phenomenon may be that EMS contains about $6 \%$ of epoxidized methyl linolenate, and the cycloaddition of epoxidized methyl linolenate with $\mathrm{CO}_{2}$ is challenging due to the three epoxides groups incorporated on the same backbone (Scheme 4). In addition, the solubility of $\mathrm{CO}_{2}$ in CMS is lower than that in the starting material, i.e. EMS. Therefore, 3.0 MPa was chosen as the optimum pressure of $\mathrm{CO}_{2}$ and the yield of CMS reached $99 \%$.

\subsection{Reaction mechanism}

Both the mixture of $\mathrm{KBr}$ and PEG (Table 1, entry 15) and the $\left[\mathrm{K}^{+}\{\mathrm{PEG}\} \mathrm{Br}^{-}\right]$complex (Scheme 2 ) showed no catalytic activity for this cycloaddition reaction. Therefore, we could conclude that iodide anion $\left(\mathrm{I}^{-}\right)$in the metal halides (e.g. KI) is crucial for the cycloaddition reaction of EMS with $\mathrm{CO}_{2}$. Also, we propose that the KI salt reacted with PEG-400 in situ to afford the $\left[\mathrm{K}^{+}\{\mathrm{PEG}\} \mathrm{I}^{-}\right]$complex, which could act as the true catalyst for such cycloaddition reactions (Scheme 5). Based on the procedure described by Kumar et al. ${ }^{29}\left[\mathrm{~K}^{+}\{\mathrm{PEG}\} \mathrm{I}^{-}\right]$was prepared as a yellow viscous oil, which was identified by UV-spectra (Fig. S1, ESI $\dagger$ ). As the complex $\left[\mathrm{K}^{+}\{\mathrm{PEG}\} \mathrm{I}^{-}\right]$was formed, the absorbance peak of the host (PEG-400) at $235 \mathrm{~nm}$ gradually reduced and a clear absorbance peak was observed at $265 \mathrm{~nm}$. $\left[\mathrm{K}^{+}\{\mathrm{PEG}\} \mathrm{I}^{-}\right]$ was then used as the catalyst in the cycloaddition reaction (Table 2). To our surprise, using PEG-400-embedded-KI (i.e. $\left.\left[\mathrm{K}^{+}\{\mathrm{PEG}\} \mathrm{I}^{-}\right]\right)$as the catalyst in the cycloaddition reaction produced only $44 \%$ yield of CMS (Table 2, entry 2), which indicates that the $\left[\mathrm{K}^{+}\{\mathrm{PEG}\} \mathrm{I}^{-}\right]$complex shows less efficiency than the combination of KI and PEG-400. The combination of $\left[\mathrm{K}^{+}\{\mathrm{PEG}\} \mathrm{I}^{-}\right]$and PEG-400 still showed less efficiency in the cycloaddition reaction (Table 2, entries 3 and 4). To our delight, good yields of CMSs (77-81\%) were obtained when the combination of $\left[\mathrm{K}^{+}\{\mathrm{PEG}\} \mathrm{I}^{-}\right](5 \mathrm{~mol} \%)$ and $\mathrm{KI}(3-5 \mathrm{~mol} \%)$ was used as the catalyst (Table 2, entries 5 and 6). Undoubtedly, free KI was crucial for this cycloaddition reaction involving epoxidized methyl soyates (EMS) as the internal epoxides. The larger molecule $\left[\mathrm{K}^{+}\{\mathrm{PEG}\} \mathrm{I}^{-}\right]$might have hampered the nucleophilic attack between an iodide anion $\left(\mathrm{I}^{-}\right)$and the internal epoxides with larger steric hindrance (EMS) (Scheme 5). In fact, some insoluble white powder (KI) was observed after the cycloaddition reaction using $\mathrm{KI}$ and $\mathrm{PEG}-400$ as the co-catalyst (KI/PEG400) (Fig. S2 in ESI $\dagger$ ). In the UV-vis spectra of $\mathrm{KI} / \mathrm{PEG}$

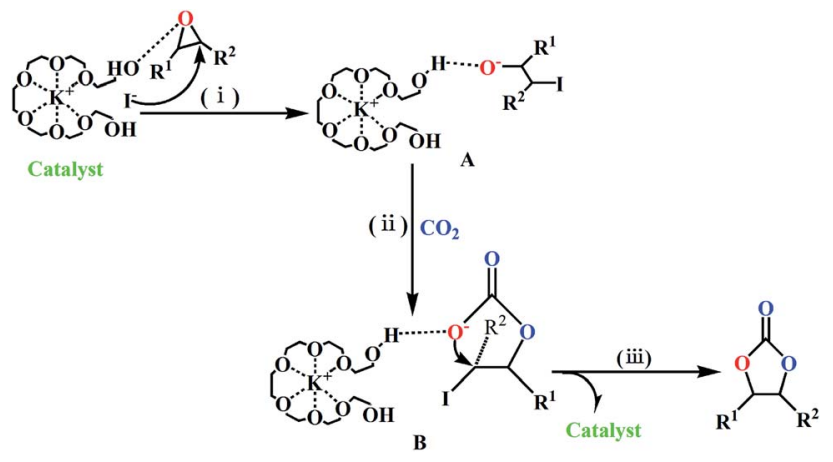

Scheme 5 Proposed mechanism through the generation of $\left[\left.\mathrm{K}^{+}\{\mathrm{PEG}\}\right|^{-}\right]$.
Table 2 Control experiments for the carbonation of $\mathrm{EMS}^{a}$

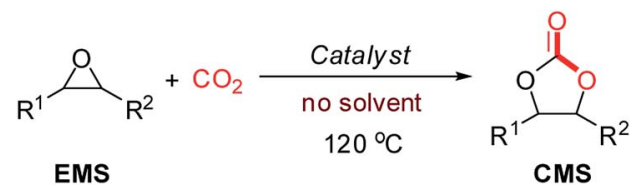

\begin{tabular}{llc}
\hline Entry & Catalyst & Yield (\%) \\
\hline 1 & $\mathrm{KI}(5 \mathrm{~mol} \%) / \mathrm{PEG}-400(5 \mathrm{~mol} \%)$ & 80 \\
2 & {$\left[\mathrm{~K}^{+}\{\mathrm{PEG}\} \mathrm{I}^{-}\right](5 \mathrm{~mol} \%)$} & 44 \\
3 & {$\left[\mathrm{~K}^{+}\{\mathrm{PEG}\} \mathrm{I}^{-}\right](5 \mathrm{~mol} \%) / \mathrm{PEG}-400(3 \mathrm{~mol} \%)$} & 44 \\
4 & {$\left[\mathrm{~K}^{+}\{\mathrm{PEG}\} \mathrm{I}^{-}\right](5 \mathrm{~mol} \%) / \mathrm{PEG}-400(5 \mathrm{~mol} \%)$} & 44 \\
5 & {$\left[\mathrm{~K}^{+}\{\mathrm{PEG}\} \mathrm{I}^{-}\right](5 \mathrm{~mol} \%) / \mathrm{KI}(3 \mathrm{~mol} \%)$} & 77 \\
6 & {$\left[\mathrm{~K}^{+}\{\mathrm{PEG}\} \mathrm{I}^{-}\right](5 \mathrm{~mol} \%) / \mathrm{KI}(5 \mathrm{~mol} \%)$} & 81 \\
${ }^{a}$ Reaction & \\
1.0 MPa, EMS: $5.0 \mathrm{~g})$. &
\end{tabular}

mixtures, the absorbance peaks of the complex $\left[\mathrm{K}^{+}\{\mathrm{PEG}\}^{-}\right]$(at $235 \mathrm{~nm}$ ) and $\mathrm{KI}$ (at $360 \mathrm{~nm}$ ) were both observed (Fig. S3 in ESI $\dagger$ ). Therefore, the in situ generation of PEG-400-embedded-KI (i.e.

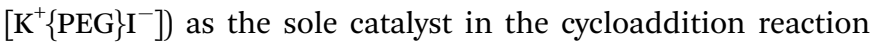
was ruled out.

\subsection{Carbonation at the $\mathrm{CO}_{2}$ pressure of 3.0 MPa}

It was found in above experiments that the yield of CMS reached 99\% under the following conditions: catalyst concentration of $8 \mathrm{~mol} \%$, reaction time of $30 \mathrm{~h}$ at $120{ }^{\circ} \mathrm{C}$ with $\mathrm{CO}_{2}$ pressure of 3.0 MPa. Thus the $\mathrm{CO}_{2}$ pressure has a significant effect on the CMS yield, and a higher $\mathrm{CO}_{2}$ pressure would increase the reaction rate of the substrate with steric hindrance, which may decrease the catalyst loading or reaction time. Because of this, the influence of catalyst concentration and reaction times on the yield of CMS under 3.0 $\mathrm{MPa} \mathrm{CO}_{2}$ pressure was explored (Table 3). The yield of CMS changed with the decrease in the catalyst concentration (Table 3, entries 1-3). It can be seen that a $99 \%$ yield of CMS could be obtained when the amount of catalyst (KI/PEG-400) was $4 \mathrm{~mol} \%$, under $\mathrm{CO}_{2}$ pressure of 3.0 MPa and with a reaction time of $30 \mathrm{~h}$. Subsequently, the reaction time was also optimized (Table 3 , entries 4 and 5). The experimental results proved that the reaction time could be shortened to $20 \mathrm{~h}$ without affecting the outcome. However, using a significantly shorter reaction time $(10 \mathrm{~h})$ led to a lower yield (85\%). Therefore, 99\% yield of CMS could be obtained in

Table 3 Optimization at the $\mathrm{CO}_{2}$ pressure of $3.0 \mathrm{MPa}^{a}$

\begin{tabular}{llll}
\hline Entry & Catalyst concentration $(\mathrm{mol} \%)$ & Time $(\mathrm{h})$ & Yield $(\%)$ \\
\hline 1 & 8 & 30 & 99 \\
2 & 4 & 30 & 99 \\
3 & 2 & 30 & 93 \\
$\mathbf{4}$ & $\mathbf{4}$ & 20 & 99 \\
5 & 4 & 10 & 85 \\
6 & 3 & 20 & 93
\end{tabular}

${ }^{a}$ Reaction conditions: reaction temperature: $120{ }^{\circ} \mathrm{C}, \mathrm{CO}_{2}$ pressure: 3.0 MPa. 


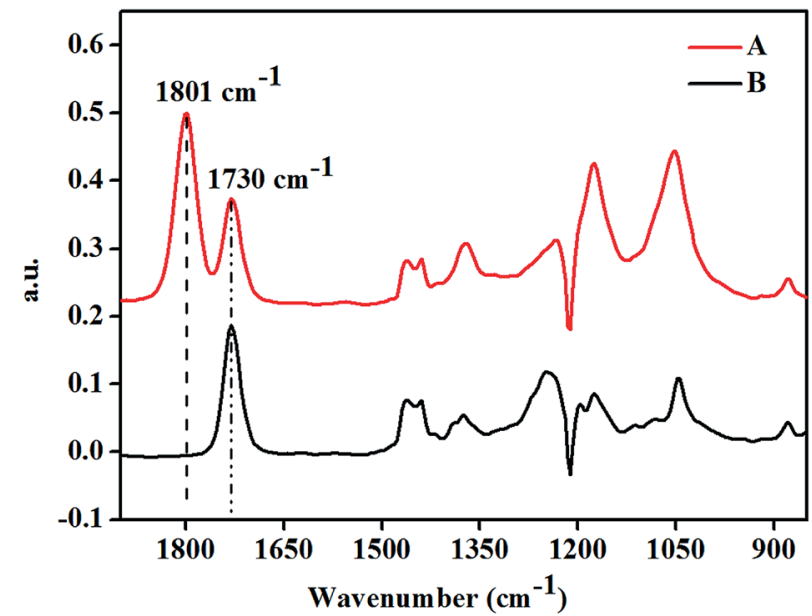

Fig. 3 FT-IR spectra after (A) and before (B) the cycloaddition reaction.

the presence of $4 \mathrm{~mol} \%$ catalyst (KI/PEG-400) with a $3.0 \mathrm{MPa}$ $\mathrm{CO}_{2}$ pressure and a reaction time of $20 \mathrm{~h}$.

\subsection{Characterization of carbonation product}

The structural features of the product of CMS were characterized by FT-IR, ${ }^{1} \mathrm{H}-\mathrm{NMR}$ and ${ }^{13} \mathrm{C}-\mathrm{NMR}$. First, we could clearly observe that the substrate before and after the cycloaddition reaction changed based on the FT-IR spectroscopy analysis (Fig. 3). The FT-IR spectra clearly showed the generation of a new bond at $1801 \mathrm{~cm}^{-1}(\mathrm{C}=\mathrm{O}$ stretching $)$, associated with the five-membered cyclic carbonate formation, which was different from the original carbonyl bond of the epoxidized methyl soyate backbone at $1730 \mathrm{~cm}^{-1}(\mathrm{C}=\mathrm{O}$ stretching). The carbonyl groups $\left(1730 \mathrm{~cm}^{-1}\right)$ of the ester bond present in both the raw material (EMS) and the final product (CMS) showed no change.

Subsequently, ${ }^{1} \mathrm{H}$-NMR was utilized to further determine the cycloaddition reaction of EMS with $\mathrm{CO}_{2}$. The ${ }^{1} \mathrm{H}-\mathrm{NMR}$ spectra of the starting material-EMS and CMS clearly indicate the

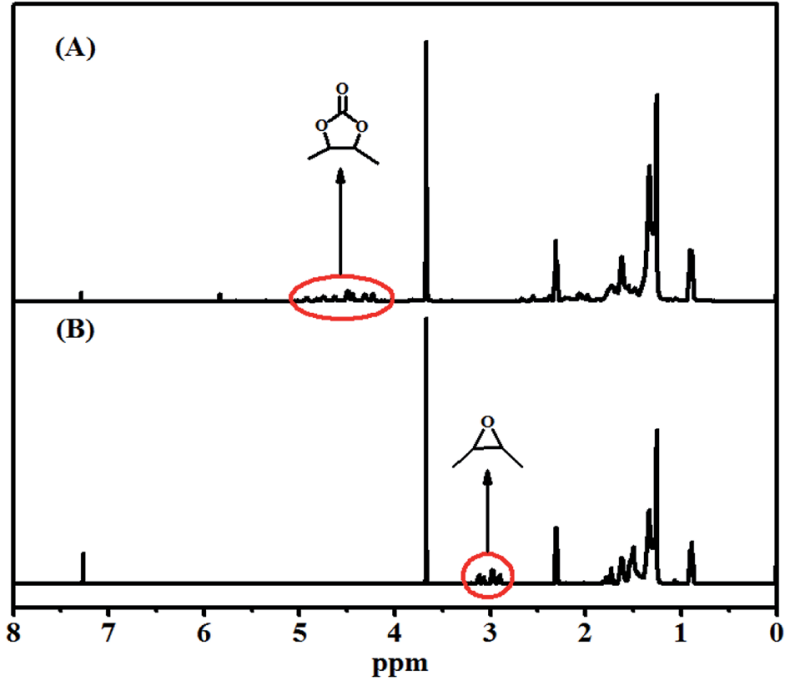

Fig. $4{ }^{1} \mathrm{H}-\mathrm{NMR}$ spectra after (A) and before (B) the cycloaddition reaction.

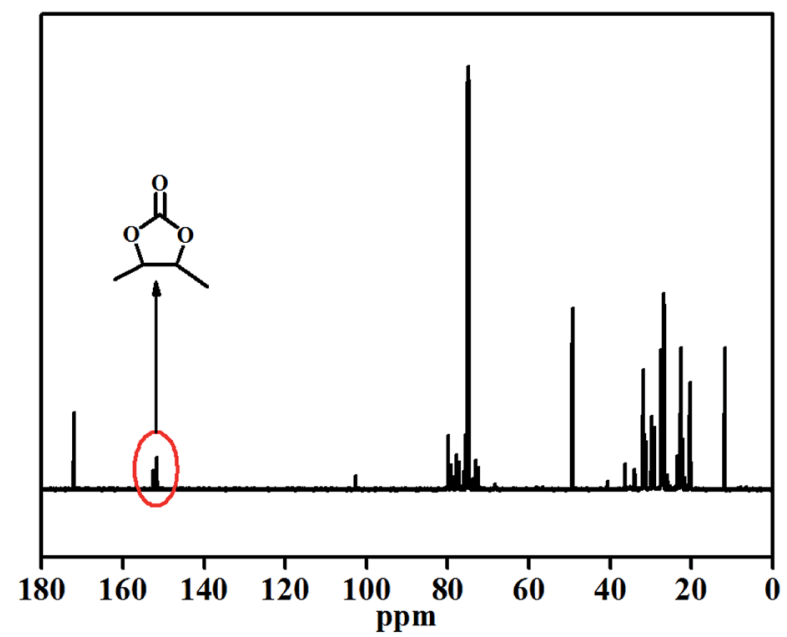

Fig. $5{ }^{13}$ C-NMR spectra of carbonated methyl soyates (CMS).

occurrence of the cycloaddition reaction of EMS with $\mathrm{CO}_{2}$, which is shown in Fig. 4. The ${ }^{1} \mathrm{H}-\mathrm{NMR}$ signals of the epoxide moiety (2.85-3.15 ppm) disappeared, while new ${ }^{1} \mathrm{H}-\mathrm{NMR}$ signals associated with the carbonate moiety emerged between 4.20$4.95 \mathrm{ppm}$.

Finally, the cycloaddition product was also identified by ${ }^{13} \mathrm{C}$ NMR spectroscopy (Fig. 5). The ${ }^{13} \mathrm{C}-\mathrm{NMR}$ spectra was obtained for CMS under the following reaction conditions: reaction temperature of $120^{\circ} \mathrm{C}$, catalyst concentration of $4 \mathrm{~mol} \%, 3.0 \mathrm{MPa}$ pressure of $\mathrm{CO}_{2}$ and reaction time of $20 \mathrm{~h}$. A new peak appeared at $154 \mathrm{ppm}$, which was associated with the carbonate moiety in the five-membered cyclic group in the final product (CMS).

\section{Conclusions}

In this work, bio-based carbonated methyl soyates (CMS) were prepared by the cycloaddition of $\mathrm{CO}_{2}$ with epoxidized methyl soyates in excellent yield using green and cheap polyethylene glycol 400 (PEG-400) and potassium iodide (KI) as co-catalyst system (4 mol\%) at $120{ }^{\circ} \mathrm{C}$ and $3.0 \mathrm{MPa}$ pressure of $\mathrm{CO}_{2}$ for $20 \mathrm{~h}$. PEG-400 possesses the characteristics of being environment friendly, cheap, green, able to capture $\mathrm{CO}_{2}$ and biodegradable compared to those of the other phase transfer catalysts (PTC). The effect of the catalyst system on cycloaddition reaction of epoxidized methyl soyates and $\mathrm{CO}_{2}$ was explored systematically, which demonstrated that the use of PEG-400 and KI could significantly promote the cycloaddition reaction of $\mathrm{CO}_{2}$ with epoxidized methyl soyates, and the yield of carbonated methyl soyates (CMS) was up to $99 \%$. In addition, the combination of PEG-400 and KI will provide a potential method to catalyze the cycloaddition reaction of $\mathrm{CO}_{2}$ and internal epoxides with larger steric hindrance to produce five-membered cyclic carbonated compounds without any solvents.

\section{Conflicts of interest}

The authors declare no competing financial interest. 


\section{Acknowledgements}

This work was supported by the China Postdoctoral Science Foundation funded project (No. 2017M622364, 2018T110730), the Henan Postdoctoral Science Foundation and Project of Henan University of Technology Excellent Young Teachers (No. 2014003).

\section{References}

1 Q. Liu, L. P. Wu, R. Jackstell and M. Beller, Using carbon dioxide as a building block in organic synthesis, Nat. Commun., 2015, 6, 5933.

2 J. Klankermayer and W. Leitner, Love at second sight for $\mathrm{CO}_{2}$ and $\mathrm{H}_{2}$ in organic synthesis, Science, 2015, 350, 629-630.

3 X. Z. Lim, How to make the most of carbon dioxide, Nature, 2015, 526, 628-630.

4 M. F. Kuehnel, D. W. Wakerley, K. L. Orchard and E. Reisner, Photocatalytic formic acid conversion on CdS nanocrystals with controllable selectivity for $\mathrm{H}_{2}$ or CO, Angew. Chem., Int. Ed., 2015, 54, 9627-9631.

5 S. Moret, P. J. Dyson and G. Laurenczy, Direct synthesis of formic acid from carbon dioxide by hydrogenation in acidic media, Nat. Commun., 2014, 5, 4017.

6 M. Marchegiani, M. Nodari, F. Tansini, C. Massera, R. Mancuso, B. Gabriele, M. Costa and N. Della Ca, Urea derivatives from carbon dioxide and amines by guanidine catalysis: easy access to imidazolidin-2-ones under solventfree conditions, J. CO2 Util., 2017, 21, 553-561.

7 Y. Liu, W. M. Ren, W. P. Zhang, R. R. Zhao and X. B. Lu, Crystalline $\mathrm{CO}_{2}$-based polycarbonates prepared from racemic catalyst through intramolecularly interlocked assembly, Nat. Commun., 2015, 6, 8594.

8 C. Maeda, T. Taniguchi, K. Ogawa and T. Ema, Bifunctional catalysts based on m-phenylene-bridged porphyrin dimer and trimer platforms: synthesis of cyclic carbonates from carbon dioxide and epoxides, Angew. Chem., Int. Ed., 2015, 54, 134-138.

9 X. D. Lang and L. N. He, Green catalytic process for cyclic carbonate synthesis from carbon dioxide under mild conditions, Chem. Rec., 2016, 16, 1337-1352.

10 J. Liang, Y. B. Huang and R. Cao, Metal-organic frameworks and porous organic polymers for sustainable fixation of carbon dioxide into cyclic carbonates, Coord. Chem. Rev., 2017, DOI: 10.1016/j.ccr.2017.11.013.

11 Z. D. Chang, X. Jing, C. He, X. Liu and C. Y. Duan, Silver clusters as robust nodes and $\pi$-activation sites for the construction of heterogeneous catalysts for the cycloaddition of propargylamines, ACS Catal., 2018, 8, 1384-1391.

12 A. A. G. Shaikh and S. Sivaram, Organic carbonates, Chem. Rev., 1996, 96, 951-976.

13 B. Schäffner, F. Schäffner, S. P. Verevkin and A. Börner, Organic carbonates as solvents in synthesis and catalysis, Chem. Rev., 2010, 110, 4554-4581.

14 O. Crowther, D. Keeny, D. M. Moureau, B. Meyer, M. Salomon and M. Hendrickson, Electrolyte optimization for the primary lithium metal air battery using an oxygen selective membrane, J. Power Sources, 2012, 202, 347-351.

15 P. Ziosi, T. Tabanelli, G. Fornasari, S. Cocchi, F. Cavani and P. Righi, Carbonates as reactants for the production of fine chemicals: the synthesis of 2-phenoxyethanol, Catal. Sci. Technol., 2014, 4, 4386-4395.

16 D. C. Webster, Cyclic carbonate functional polymers and their applications, Prog. Org. Coat., 2003, 47, 77-86.

17 J. A. Kenar, G. Knothe, R. O. Dunn, T. W. Ryan and A. Matheaus, Physical properties of oleochemical carbonates, J. Am. Oil Chem. Soc., 2005, 82, 201-205.

18 N. V. Maksimchuk, I. D. Ivanchikova, A. B. Ayupov and O. A. Kholdeeva, One-step solvent-free synthesis of cyclic carbonates by oxidative carboxylation of styrenes over a recyclable Ti-containing catalyst, Appl. Catal., B, 2016, 181, 363-370.

19 T. Sakakura and K. Kohno, The synthesis of organic carbonates from carbon dioxide, Chem. Commun., 2009, 11, 1312-1330.

20 Z. R. Li, Y. H. Zhao, S. R. Yan, X. K. Wang, M. Q. Kang, J. W. Wang and H. W. Xiang, Catalytic synthesis of carbonated soybean oil, Catal. Lett., 2008, 123, 246-251.

21 C. A. Montoya, A. B. Paninho, P. M. Felix, M. E. Zakrzewska, J. Vital, V. Najdanovic-Visak and A. V. M. Nunes, Styrene carbonate synthesis from $\mathrm{CO}_{2}$ using tetrabutylammonium bromide as a non-supported heterogeneous catalyst phase, J. Supercrit. Fluids, 2015, 100, 155-159.

22 J. A. Castroosma, K. J. Lamb and M. North, Cr(salophen) complex catalyzed cyclic carbonate synthesis at ambient temperature and pressure, ACS Catal., 2016, 6, 5012-5025.

23 F. D. Bobbink and P. J. Dyson, Synthesis of carbonates and related compounds incorporating $\mathrm{CO}_{2}$ using ionic liquidtype catalysts: state-of-the-art and beyond, J. Catal., 2016, 343, 52-61.

24 H. Büttner, J. Steinbauer, C. Wulf, M. Dindaroglu, H. G. Schmalz and T. Werner, Organocatalyzed synthesis of oleochemical carbonates from $\mathrm{CO}_{2}$ and renewables, ChemSusChem, 2017, 10, 1076-1079.

25 W. Desens and T. Werner, Convergent activation concept for $\mathrm{CO}_{2}$ fixation in carbonates, Adv. Synth. Catal., 2016, 358, 622-630.

26 Y. Du, J. Q. Wang, J. Y. Chen, F. Cai, J. S. Tian, D. L. Kong and L. N. He, A Poly(ethylene glycol)-supported quaternary ammonium salt for highly efficient and environmentally friendly chemical fixation of $\mathrm{CO}_{2}$ with epoxides under supercritical conditions, Tetrahedron Lett., 2006, 47, 12711275.

27 J. Steinbauer and T. Werner, Poly(ethylene glycol)s as ligands in calcium-catalyzed cyclic carbonate synthesis, ChemSusChem, 2017, 10, 3025-3029.

28 S. Kaneko and S. Shirakawa, Potassium iodide-tetraethylene glycol complex as a practical catalyst for $\mathrm{CO}_{2}$ fixation reactions with epoxides under mild conditions, ACS Sustainable Chem. Eng., 2017, 5, 2836-2840.

29 S. Kumar and S. L. Jain, Polyethylene glycol wrapped potassium bromide assisted chemical fixation of carbon dioxide, Ind. Eng. Chem. Res., 2014, 53, 541-546. 
30 B. Schäffner, M. Blug, D. Kruse, M. Polyakov, A. Köckritz, A. Martin, P. Rajagopalan, U. Bentrup, A. Brückner, S. Jung, D. Agar, B. Rüngeler, A. Pfennig, K. Müller, W. Arlt, B. Woldt, M. Graß and S. Buchholz, Synthesis and application of carbonated fatty acid esters from carbon dioxide including a life cycle analysis, ChemSusChem, 2014, 7, 1133-1139.

31 J. Tharun, G. Mathai, A. C. Kathalikkattil, R. Roshan, J. Y. Kwak and D. W. Park, Microwave-assisted synthesis of cyclic carbonates by a formic acid/KI catalytic system, Green Chem., 2013, 15, 1673-1677.

32 M. E. Wilhelm, M. H. Anthofer, M. Cokoja, I. I. E. Markovits, W. A. Herrmann and F. E. Kühn, Cycloaddition of carbon dioxide and epoxides using pentaerythritol and halides as dual catalyst system, ChemSusChem, 2014, 7, 1357-1360.

33 S. G. Liang, H. Z. Liu, T. Jiang, J. L. Song, G. Y. Yang and B. X. Han, Highly efficient synthesis of cyclic carbonates from $\mathrm{CO}_{2}$ and epoxides over cellulose/KI, Chem. Commun., 2011, 47, 2131-2133.

34 J. L. Song, Z. F. Zhang, B. X. Han, S. Q. Hu, W. J. Li and Y. Xie, Synthesis of cyclic carbonates from epoxides and $\mathrm{CO}_{2}$ catalyzed by potassium halide in the presence of $\beta$ cyclodextrin, Green Chem., 2008, 10, 1337-1341.
35 J. Martínez, J. Fernández-Baeza, L. F. Sánchez-Barba, J. A. Castro-Osma, A. Lara-Sánchez and A. Otero, An efficient and versatile catalyst for carbon dioxide fixation into cyclic carbonates, ChemSusChem, 2017, 10, 2886-2890.

36 A. F. Guzman, D. A. Echeverri and L. A. Rios, Carbonation of epoxidized castor oil: a new bio-based building block for chemical industry, J. Chem. Technol. Biotechnol., 2017, 92, 1104-1110.

37 N. Tenhumberg, H. Büttner, B. Schäffner, D. Kruse, M. Blumenstein and T. Werner, Cooperative catalyst system for the synthesis of oleochemical cyclic carbonates from $\mathrm{CO}_{2}$ and renewables, Green Chem., 2016, 18, 37753788.

38 M. Vafaeezadeh and M. M. Hashemi, Polyethylene glycol (PEG) as a green solvent for carbon-carbon bond formation reactions, J. Mol. Liq., 2015, 207, 73-79.

39 W. V. T. Madhushani, Y. M. C. D. Jayathilake, K. S. Perera and K. P. Vidanapathirana, Effect of cation size of iodide salt in the electrolyte on the performance of dye sensitised solar cells, J. Natl. Sci. Found. Sri Lanka, 2016, 44, 77-81.

40 X. S. Cai, J. L. Zheng, J. Wärnå, T. Salmi, B. Taouk and S. Leveneur, Influence of gas-liquid mass transfer on kinetic modeling: carbonation of epoxidized vegetable oils, Chem. Eng. J., 2017, 313, 1168-1183. 